\title{
The power process and emotion
}

\author{
EDWARD J. LAWLER AND CHADA. PROELL
}

\section{Introduction}

Power is a crucial phenomenon in organizations, both pervasive and somewhat elusive. The study of power in organizations has a long tradition (Crozier 1964), yet the literature on power is fragmented and has been a central focus only intermittently over time. Fundamental assumptions about the role of power vary widely. On the one hand, power can be construed broadly as a negative and divisive force in relations, groups, and organizations. It enables those having power to exert influence over or command the compliance of others through coercion, force, and threats. This is the punitive, manipulative face of power (Deutsch and Krauss 1962; Lawler et al. 1988; Tedeschi et al. 1973). On the other hand, power can be construed as a positive, integrative force enabling those with power to provide rewards, inducements, and reinforcements to others (Bacharach and Lawler 1980; Boulding 1989). It gives those with power the opportunity to promote cooperation and collaboration. The negative view of power emphasizes the harm it can do and the resistance it can generate, whereas the positive view of power emphasizes the role of power in mobilizing concerted action toward collective goals. Implicitly, negative and positive emotions (e.g., pleasure, enthusiasm, pride or anger, fear, sadness) are likely to be associated, respectively, with the negative and positive faces of power. This chapter proposes a powerprocess model for examining the relationship between power and emotion.

Recent work on power and emotion can be found within three disparate lines of theory and research:

1. social-exchange theory in sociology (Lawler and Thye 1999);

2. "approach inhibition" theory in psychology (Keltner et al. 2003);

3. research on negotiations from organizational behavior (Carnevale and Isen 1986). 
Unfortunately, these literatures have existed largely in isolation. This chapter draws ideas from each and fleshes out the role emotions play in power relations. We provide exemplars of research falling within these research traditions but, due to space limitations, we do not undertake a comprehensive review. Our purposes are primarily conceptual. This chapter presents a power-process model designed to integrate elements from different approaches to power. In the context of this power-process model, we highlight some of the conclusions about power and emotion that can be drawn from work on power dependence structures, the approach/ inhibition effects of power, and the role of emotions, felt or expressed, in negotiation settings. We propose that the power-process model can not only integrate ideas from widely disparate literatures but also reveal gaps and suggest problems and issues for future study.

The first step, however, is to define emotion. A review of the psychological and sociological literatures reveals an almost endless array of variation in how emotion, affect, feelings, moods, and sentiments are used (Lawler 2007). We adopt a commonly used definition of emotions as transitory positive or negative evaluative states with physiological, neurological, and cognitive components (Izard 1991; Kemper 1978). Emotions are a nonconscious response to external stimuli whereas feeling emotions involves at least a minimal awareness of the bodies' response to the stimuli (Damasio et al. 2000). We use the terms "emotions" and "feelings" interchangeably and focus on generalized emotions or feelings that people develop in interaction or exchange with others. Such emotions involve feeling good, feeling pleasure, or feeling happy, rather than more specific emotions directed at self or other such as pride or gratitude (Lawler 2001; Weiner 1985). Affect is generally construed as a broader term than emotion (see Brief and Weiss 2002). It subsumes the generalized feelings of concern described here, as well as more enduring emotional states such as moods (which are diffuse feelings without targets) and sentiments (which target self, other, or groups) (Lawler 2007). Unless otherwise noted, we limit the scope of our analysis to short-term emotional states while recognizing that in dealing with recurrent interactions or exchanges, the distinction between transitory and enduring affective states tends to blur.

\section{A power process model}

Most definitions of power focus on social power. What makes power social is that it is a property of a relationship between two or more 


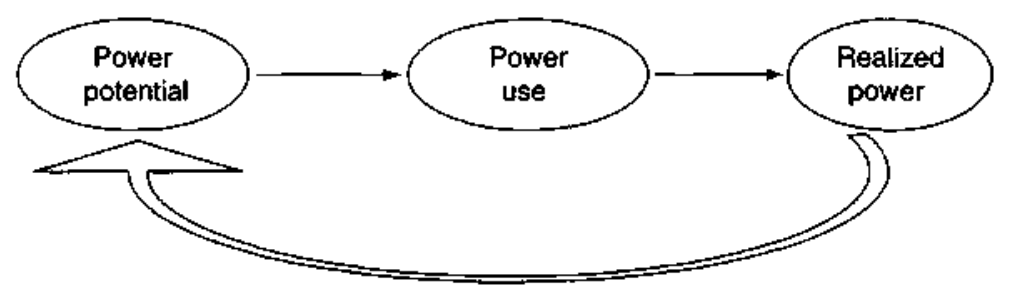

Feedback toop

Figure 10.1 Power process model.

individuals, i.e. to have power is to have power over someone else (Brass and Burkhardt 1993; Emerson 1962; French and Raven 1959; Ng 1980). Most concepts of power also include one or more of the following: (1) a capability or potential; (2) behaviors using that capability; (3) the impact of using the capability (actual or realized power and influence). The first typically involves a structure (e.g., network or hierarchy) within which a position provides an actor resources that are of value to one or more others (Cook and Emerson 1978; Emerson 1972). The second typically involves tactics or strategies designed to shape or change the behavior of another (Bacharach and Lawler 1981; Molm 1990). The third involves successful or unsuccessful influence over that other. Lawler (1992) incorporated all three of these facets or dimensions into a "power process model" which informs this paper. This model is diagrammed in Figure 10.1.

In the power-process model, each facet should be thought of as one "moment" of an integrated process. An actor faces a "problem" that involves influencing another; the actor has a resource (capability) that the other values, a range of behavioral options (tactics) for using this resource, and an outcome or result that is desired (Lawler 1992). Power capabilities underlie power use, and power use is the basis for actual power. One advantage of this model is that it makes fewer a-priori assumptions than most power frameworks, especially those that conflate power and its effects (see Dahl 1957). Rather than presuming that a capability is used, this model implies that there may be conditions under which having a capability is sufficient to influence another in the absence of power use. Whether or not it is used becomes a theoretical and empirical question. Rather than assuming that power produces results that favor the more powerful, the model implies that this depends on how the power is used (i.e. the tactics chosen) and the 
amount and type of resistance generated by lower power actors. For example, low-power actors may have more influence than their power position would suggest because they are highly motivated to devise effective tactics (Bacharach and Lawler 1980), or because they more carefully process and weigh information on the high-power person (Fiske 1993). Thus, by making sharp distinctions between these complementary facets of power, the power-process model poses questions that many other frameworks on power define away.

An implication is that in almost any social relationship, individuals are likely to have some capacity to affect each other, a variety of options for using that capability, and an uncertain probability of success (Lawler 1992: 20). Emotions can enter the power process at all three points. If $\mathrm{A}$ has a power capability, it may arouse a fear of negative sanctions or the hope of positive reward; if $A$ uses his or her power, the tactics chosen could affect the emotions felt by the other and perhaps those of the actor using the tactic; and if a successful result is generated, the emotions felt by self and other may depend on the degree that they each receive benefits from A's successful influence. The three moments of the power process and prospective emotional effects can be tied in part to underlying dependencies and interdependencies (Bacharach and Lawler 1980; Emerson 1972; Thibaut and Kelley 1959). These can be fruitfully analyzed from power-dependence theory (Bacharach and Lawler 1981; Emerson 1962, 1972).

\section{Power as dependence}

Power-dependence theory, developed originally by Emerson (1962, 1972 , is based on a very simple idea: The power of $A$ is based on the dependence of $B$ on $A$ for valued outcomes, and vice versa. The degree of $A$ 's power over $B$ depends on how much $B$ values what $A$ provides and the degree that $B$ does not have alternative persons or relations from which to acquire these valued outcomes. The relational nature of power dependence emphasizes the point that power relations are two-way, involving mutual dependencies or interdependencies (see also Thibaut and Kelley 1959), and should be analyzed in these terms.

Importantly, Emerson's (1972) framework implies a non-zero-sum conception of power in which each actor's power in a relation can grow or decline; thus an increase in one actor's power does not by definition reduce the other's power. Bacharach and Lawler (1981) developed the 
non-zero-sum implications of Emerson's (1972) framework by distinguishing the relative power (dependence) of actors from the rotal power (dependence) in the relationship. Relative power refers to the degree of difference between A's dependence on B and B's dependence on A, whereas total power refers to the sum of each actor's dependence on the other (see also Molm 1987). Total power or dependence in a relation can vary because each actor's alternatives may contract or expand, and the value of the outcomes at stake also may grow or decline over time. Bacharach and Lawler (1981) use the distinction between relative and total power to develop the positive face of power. If actors have equal power and they build greater total power into their relationship, they have more to gain from repeated exchange or collaboration. They can accomplish joint goals together more effectively, more quickly, and with fewer costs. If actors have unequal power but increase the total power or dependence in their relationship, a similar result is likely to occur because there are stronger incentives for collaboration (Piskorski and Tiziana 2006).

A non-zero-sum approach to power has implications for the emotions felt by actors in exchange. All things being equal, one would expect equal power dependence to generate more positive feelings about exchange with another than unequal power. Higher total power in the relation should also produce more positive emotions than lower total power. The rationale for the former is that equal power conditions avoid the issues of justice and legitimacy that tend to occur under unequal power conditions. The rationale for the latter is that the interaction or exchange generates greater joint gain. Overall, it is reasonable to hypothesize that equal power and high total power will enhance the total amount of positive affect in a relationship. Theory and research on relational cohesion suggests how this might occur.

\section{Relational cobesion}

Lawler and colleagues (Lawler and Yoon 1993, 1996) developed a theory of relational cohesion that incorporates both zero-sum and non-zero-sum components of power dependence and shows how each of these affect the emotions generated from social exchange. Specifically, they proposed that equal and high total power would generate more frequent exchange, and frequent or repeated exchanges would be a basis for enduring exchange relations because of emotions 
generated by successful exchanges. This is theorized to occur because coming to an agreement is an accomplishment that makes the actors feel good. These positive emotions, when felt or experienced repeatedly, generate perceptions of a unifying, cohesive relation which the actors are then motivated to maintain net of the effects of the exchange outcomes themselves (see Lawler and Yoon 1993, 1996). The result is commitment behavior directed at the social unit in question (the relation). A series of studies by Lawler and colleagues supports the predictions of relational cohesion theory (e.g., Lawler et al. 2000; Lawler and Yoon 1993, 1996, 1998). In sum, both equal and higher total power produce more positive emotions than unequal and lower total power, and these promote stronger relationships.

It is important to point out, however, that repeated exchanges (frequency) generate positive feelings and more cohesion/commitment even under most unequal power conditions (Lawler and Yoon 1998). As long as exchange generates positive emotions to some degree, repeated exchanges build relations even under unequal power (see Thye et al. 2007). The only exception to this pattern has been when one actor has extremely low power; here exchanges do not generate positive emotions or feelings (see Lawler and Yoon 1998). In terms of the power-process model, this research shows how and when power potential promotes mutually felt positive emotions by repeatedly producing exchange outcomes. These emotional reactions shape whether actors attempt to maintain the relation over time.

There also is research in the exchange tradition suggesting that under unequal power, the results of the power process have different emotional effects on the low- and high-power actors (Lawler and Yoon 1993; Molm 1997). With this in mind, Lovaglia and colleagues (Lovaglia 1994, 1995a, 1995b; Lovaglia and Houser 1996; Willer et al. 1997) investigated the hypothesis that the exercise or demonstration of power should lead to enhanced status for the higher-power actor (Emerson 1962; Lovaglia 1994). The results indicated, however, that the relationship between power and status is complicated by the emotional responses of the low-power actor to the exercise of power by the high-power actor. Specifically, if low-power actors reacted with negative emotions to the exercise of power (defined as garnering higher individual profits), this actually decreased the high-power actor's status and influence (Lovaglia and Houser 1996; Willer et al. 1997). Thus, while Lawler and colleagues' work indicates that exchanges made under 
unequal power conditions can generate positive emotions separate from the outcome and help to build collaborative relations, the work by Lovaglia and colleagues suggests that negative emotions from the results of exchange may obstruct this process. In terms of the power-process model, the important point is that realized power is connected to the generation of emotions, and these emotions produce feedback effects from the outcome to the future capability.

\section{Use of power}

The network-oriented power-dependence approach of Emerson (1972) tends to downplay the tactics of using power. Emerson assumes that if actors have power, they will use power, thereby conflating the first two moments of our power-process model (see Figure 10.1). Extant research explicitly on power and emotion has also downplayed tactics (see Lawler and Yoon 1993, 1996, 1998); an exception is the work by Molm (1991, 1997) who has explicitly compared coercive and reward tactics by high- and low-power actors in a network. She found that coercive tactics evoke negative emotional reactions while reward tactics evoke positive emotions and, importantly, that the negative emotional responses to coercive tactics was stronger than the positive emotional responses to reward tactics. Moreover, she found that those in disadvantaged positions were more likely to use coercive tactics against the higher power actor than vice versa, and that those in a poweradvantaged position reacted more negatively to such coercion than those in a power-disadvantaged position (Molm 1997).

Proell (2007) recently used the power-process model to explore an alternative approach to power and status from that of Lovaglia et al. (Lovaglia 1994, 1995a; Lovaglia and Houser 1996; Willer et al. 1997). Drawing upon the French and Raven (1959), Kipnis (Kipnis and Schmidt 1988; Kipnis et al. 1980) and Yukl (Yukl and Falbe 1990; Yukl and Tracey 1992) tradition of influence tactics, as well as Lawler's (1992) broad classification of tactics as positive (signaling cooperative motives) and negative (signaling competition), Proell found that the emotion generated from the exercise of power depended on the type of tactic used. Positive tactics, such as ingratiation, elicited more positive emotions, whereas negative tactics, such as coalitions, elicited more negative emotions. Moreover, reaction to the tactics depended upon the status of the person using the tactic. Coalition tactics by 
high-status persons evoked more negative reactions from low-status targets than did coalition tactics of low status directed at high-status targets. Thus, it appears that both structurally determined power (Molm 1991) and the status of the actor using the tactic moderate emotional reactions to tactic use.

In terms of the power-process model, both the work of Molm and Proell indicate that emotions are linked to the tactics chosen. This work also indicates why it is important to avoid the conflation of power potential and power use. Emotional reactions to tactics are partially contingent upon the circumstances surrounding the tactic use, including the power potential of the actor engaging in the tactic. Moreover, this research, combined with the findings of Lovaglia and colleagues (1996) and Lawler and colleagues (1993, 1996, 1998), underscores the importance of the positive face of power. Negative tactics generate negative emotions which potentially undermine the stability of an exchange relationship, whereas positive tactics generate positive emotions which should reinforce an exchange relationship. Put differently, feedback loops involving positive emotions from tactics to power potential should strengthen an actor's future power potential, whereas negative feedback loops involving negative emotions should decrease that power potential and ultimately challenge the stability of an exchange relationship.

One salient limitation of work in the exchange tradition is that little attention has been given to the spread of emotions across individuals, i.e. emotional contagion. Emotional contagion is the transfer of emotions from individual to individual (Schoenewolf 1990). A good deal of work demonstrates that the emotions of actors in a relationship tend to converge over time (Bartel and Saavedra 2000; Totterdell 2000; Totterdell et al. 1998). In fact, not only do emotions converge with repeated interaction, but Anderson et al. (2003) show that it is the low-power actor whose emotion converges toward the high-power actor. The implications for repeated exchange are potentially quite large. High-power actors who are happy with their resource gains may actually promote more happy feelings among low-power actors than their outcomes would indicate because their emotions are converging toward those of the high-power actors. This might serve to strengthen the stability or cohesion of unequal power relationships in the workplace. Conversely, an unhappy high-power actor, regardless of the source of unhappiness, may undermine the cohesion of an unequal 
exchange relationship and even set off conflict spirals similar to those studied by O'Connor and Arnold (2001). Future work should address more systematically the contagion effects that can occur when people interact and exchange to achieve collective goals.

\section{Experiencing power: approach/avoidance processes}

Recent work in psychology has used approach/avoidance theory to examine how the experience of power affects the propensity toward initiating action to deal with a problem or issue. In terms of the power-process model, such power-to-action effects capture a process underlying the potential-to-use link. Approach/inhibition work seeks to understand when action is actually undertaken to use power. The approach/inhibition theory of power is inspired in part by the work of Kipnis (1976) in that it is concerned with how the possession of power affects the behavior of the power-holder (see Keltner et al. 2003 for a review).

Put simply, the theory argues that the environment of high-power actors consists of more rewards, opportunities, and freedom. Because high-power agents are enmeshed in a reward-rich environment, with substantial opportunities for and freedom of action, approach-related tendencies are automatically and subconsciously activated (see Keltner et al. 2003 for a review). These approach tendencies are in turn associated with automatic cognition, attention to rewards, and a propensity toward action. Conversely, the environment of low-power actors consists of less freedom, fewer opportunities, and more threat which automatically and subconsciously trigger inhibition-related tendencies. These inhibition tendencies, in turn, are associated with systematic cognition, attention to threats, and a propensity away from action. Important for our purposes, approach tendencies are also associated with positive emotion (Davidson 1992; Higgins 1997) whereas inhibition tendencies are associated with negative emotion (Carver and White 1994). Thus, elevated power leads to the experience and expression of positive emotions, and decreased power leads to the experience and expression of negative emotions.

This work predicts overall that individuals with high-power potential will be more likely to use their power than low-power individuals. Similarly, affectemotion enters the power process at the power-potential stage of the power-process model. Those high in power potential are also high in positive affect and they express those emotions more freely than 
those low in potential power. Galinsky et al. (2003) found support for the predicted power-to-action effects - namely that individuals primed with high power and given more potential power in terms of their ability to allocate resources were more likely than those who lacked power to take action to solve a problem. However, this work did not specifically address the emotions involved. Work by Anderson and Berdahl (2002), however, found that individuals assigned to a high-power position on a committee determining resource allocations, experienced approach tendencies and positive emotions while individuals assigned to a lowpower committee position experienced inhibition tendencies and negative emotion. Similarly, Berdahl and Martorana (2006) found that high-power actors did experience and express more positive emotions and less anger than did low-power actors in a controversial group conversation. Thus, research suggests that the mere experience of high and low power potential has relevant implications for both the powerpotential-to-power-use connection as well as the power-potential-toemotion connection. While there is growing support for the predictions of the approach/inhibition theory of power in general (e.g., Galinsky et al. 2003), the investigation of the power-to-emotion predictions have only recently begun.

Viewing work on approach/inhibition theory from the powerprocess model, one limitation is that although this research does focus on when power potential may lead to power use, it does not predict which tactics will be chosen when power is used. For example, because high-power actors are also in a more positive affective state, is it the case that they are more likely to engage in positive tactics than low-power actors in a relationship? Conversely, because low-power actors are in a negative affective state, are they prone to select negative or punishing strategies? This is suggested by Molm's (1997) work. Whereas one advantage of this literature over the exchange tradition is that it specifically theorizes and empirically examines the power-potential-topower-use connection, exchange theory does a better of job of connecting power use to results and results to emotions. These two theoretical approaches are complementary, and emotional processes may be a point of integration. For example, the results or outcomes of exchange may generate approach or inhibition tendencies, as well as the possession or experience of power potential.

Another limitation of the approach/avoidance approach to power is its strong focus on unequal power relationships. The experience of 
power is based on having more power than someone else. This emphasis on unequal power ignores the non-zero-sum implications of powerdependence theory. Because the total power in a relationship may vary, individuals may experience equal power relationships, yet the individual actors may still be prone to feeling high or low power. A potentially important question is whether this type of relationship translates into the approach/inhibition emotion tendencies described by Keltner et al. (2003). In other words, are the effects of relative and total power consistent with each other? Under higher total power, will both actors have approach tendencies, whereas under lower total power will they both have inhibition tendencies? Questions such as these would move forward research on the experience of power and emotion but could also tie this research more closely to the exchange tradition and potentially create other opportunities for cross-fertilization.

\section{Emotions as a basis for power}

Recently, a small body of negotiation research has examined emotions as tactics. The orienting idea is that emotions or emotional expressions can be used strategically or tactically to produce desired outcomes (Frank 1988), thus resulting in increased or decreased power. Applying our power-process model, the focus here is on the useto-realized-power link. This research tends to involve one-shot negotiations and emphasize realized power, that is, resources produced as a result of negotiation. Thus, the evidence on increasing or decreasing power is indirect, since the emotion-to-power-potential effects presume that realized power in a single negotiation carries over to subsequent negotiations or exchanges. Assuming that an increase in realized power does carry meaning for subsequent exchanges, there are two relevant issues addressed by this literature: (a) value-creation as a result of experiencing emotions and (b) value-claiming as a result of emotional displays. Each is briefly discussed below.

With regard to value creation, a seminal study by Carnevale and Isen (1986) found that negotiators primed with positive affect, via the reading of humorous cartoons, communicated more openly, assessed the other's priorities more accurately, and created more value (i.e. had more integrative agreements) than negotiators not primed with positive affect. These results have been replicated (Baron 1990; Forgas 1998; Kramer et al. 1993) and extended to show that negative affect 
correspondingly reduces joint outcomes (Allred et al. 1997). This work was extended further in an important way by Anderson and Thompson (2004), who showed that, in unequal power relations, it is the highpower negotiator's positive emotion that leads to a better integrative outcome, not the emotions of the low-power negotiator. Overall, interpreting integrative outcomes as realized total power, the experience of positive and negative affect appears to play a central and important role in how much total power a relationship develops, but this is due primarily to the emotion or affect of the high-power negotiator.

Turning to the claiming of value in negotiations, research consistently finds that the display of negative emotion in the form of anger results in the successful claiming of more resources. For example, Van Kleef et al. (2004) found that in computer-mediated negotiations, information about a counterpart's angry emotional state led negotiators to make fewer demands of and more concessions to their counterpart than when information about a counterpart's positive emotions were made available. Importantly however, Sinaceur and Tiedens (2006) show that this effect is moderated by the power positions of the negotiators. Lowpower negotiators concede more to an angry counterpart but there are no significant effects for anger display on high power counterparts (Van Kleef et al. 2006). Thus, because high-power negotiators can gain more power and low-power negotiators can lose power via displays of anger, as a strategic tool, anger most likely serves to further exacerbate power inequalities rather than balance power relationships. In sum, the evidence from the negotiations literature suggests that negative emotions (in particular anger) are often effective tactics for generating realized power, whereas positive emotions are effective tactics for creating joint value. These broad implications are generally consistent with socialexchange research on power and emotion in the relational cohesion tradition (e.g., Lawler and Yoon 1993, 1996).

\section{Conclusions}

Understanding the relationships of power and emotion is in its infancy, despite significant growth of attention in the fields of sociology, psychology, and organizational behavior. To date, emotion has served primarily as an explanatory mechanism for other processes, such as the emergence of commitment in social exchange (e.g., Lawler and Yoon 1996) or as an ancillary consequence or byproduct of power 
relations (e.g., Keltner et al. 2003). Using our power-process model as a framework, it is clear that many questions remain unanswered and there are gaps to be filled, theoretically and empirically. It is also clear how disparate work on specific links of the power process model can fit together and be interrelated. There are good reasons for having distinct theories and research on particular parts of the model (e.g., power to action, tactics to power, outcomes to power potential), but it is also important to have a broader framework for integrating distinct lines of work. Future research should theorize more systematically the interrelationships of these component parts of the power-process model. The distinct moments of our power-process model suggest a wide range of issues and questions to be dealt with in future work. We hope this paper will help to encourage more sustained and systematic attention to the multitude of ways that power and emotion are intertwined.

\section{References}

Allred, K.G., Mallozzi, J. S., Matsui, F., and Raia, C.P. (1997) The influence of anger and compassion on negotiation performance. Organizational Behavior and Human Decision Processes, 70 (3), 175-187.

Anderson, C. and Berdahl, J. L. (2002)The experience of power: Examining the effects of power on approach and inhibition tendencies. Journal of Personality and Social Psychology, 83 (6), 1362-1377.

Anderson, C., Keltner, D., and John, O.P. (2003) Emotional convergence between people over time. Journal of Personality and Social Psychology, 84 (5), 1054-1068.

Anderson, C. and Thompson, L. L. (2004) Affect from the top down: How powerful individuals' positive affect shapes negotiations. Organizational Behavior and Human Decision Processes, 95 (2), 125-139.

Bacharach, S. B. and Lawler, E. J. (1980) Power and politics in organizations, San Francisco, Calif.: Jossey-Bass.

(1981) Bargaining, power, tactics, and outcomes, 1st edn, San Francisco, Calif.: Jossey-Bass.

Baron, R. A. (1990) Environmentally induced positive affect: Its impact on self-efficacy, task-performance, negotiation, and conflict. Joutnal of Applied Social Psychology, 20 (5), 368-384.

Barsade, S. G. (2002) The ripple effect: Emotional contagion and its influence on group behavior. Administrative Science Quarterly, 47 (4), 644-675.

Bartel, C. A. and Saavedra, R. (2000) The collective construction of work group moods. Administrative Science Quarterly, 45 (2) 197-231. 
Berdahl, J.L. and Martorana, P. (2006) Effects of power on emotion and expression during a controversial group discussion. European Journal of Social Psychology, 36 (4), 497-509.

Boulding, K.E. (1989) Three faces of power, Newbury Park, Calif.: Sage Publications.

Brass, D. J. and Burkhardt, M.E. (1993) Potential power and power use: An investigation of structure and behavior. Academy of Management Journal, 36 (3), 441-470.

Brief, A.P. and Weiss, H.M. (2002) Organizational behavior: Affect in the workplace. Annual Review of Psychology, 53, 279-307.

Carnevale, P.J.D. and Isen, A.M. (1986) The influence of positive affect and visual access on the discovery of integrative solutions in bilateral negotiation. Organizational Behavior and Human Decision Processes, $37(1), 1-13$.

Carver, C.S. and White, T.L. (1994) Behavioral-inhibition, behavioral activation, and affective responses to impending reward and punishment - the bis bas scales. Journal of Personality and Social Psychology, 67 (2), 319-333.

Collins, C. (2004) Interaction ritual chains, Princeton, N. J.: Princeton University Press.

Cook, K.S. and Emerson, R.M. (1978) Power, equity and commitment in exchange networks. American Sociological Review, 5, 721-739.

Crozier, M. (1964) The beuracratic phenomenon, Chicago, Ill.: University of Chicago Press.

Dahl, R. A. (1957) The concept of power. Behavioral Science, 2 (3), 201-215. Damasio, A.R., Grabowski, T.J., Bechara, A., Damasio, H., Ponto, L.L. B., Parvizi, J., et al. (2000) Sulcortical and cortical brain activity during the feeling of self-generated emotions. Nature Neuroscience, 3 (10), 1049-1056.

Davidson, R. J. (1992) Emotion and affective style: Hemispheric substrates. Psychological Science, 3 (1), 39-43.

Deutsch, M. and Krauss, R.M. (1962) Studies of interpersonal bargaining. Journal of Conflict Resolution, 6, 52-76.

Emerson, R. M. (1962) Power-dependence relations. American Sociological Review, 27 (1), 31-41.

(1972) Exchange theory, part II: Exchange relations, exchange networks, and groups as exchange systems. In J. Berger, M. Zelditch, and B. Anderson (Eds.), Sociological theories in progress (Vol. II, pp. 58-87), Boston, Mass.: Houghton Mifflin.

Fiske, S. T. (1993) Controlling other people: The impact of power on stereotyping. American Psychologist, $48(6), 621-628$.

Forgas, J.P. (1998) On feeling good and getting your way: Mood effects on negotiator cognition and bargaining strategies. Journal of Personality and Social Psychology, 74 (3), 565-577. 
Frank, R.H. (1988) Passions within reason: The strategic role of emotions, New York, N.Y.: Norton.

French, J.R.P. Jr. and Raven, B. (1959) The bases of social power. In D. Cartwright (Ed.), Studies of social power (pp. 150-167), Ann Arbor, Mich.; Institute for Social Research.

Galinsky, A.D., Gruenfeld, D. H., and Magee, J.C. (2003) From power to action. Journal of Personality and Social Psychology, 85 (3), 453-466.

Higgins, E. T. (1997) Beyond pleasure and pain. American Psychologist, 52 (12), 1280-1300.

Isen, A. M., Daubman, K. A., and Nowicki, G. P. (1987) Positive affect facilitates creative problem solving. Journal of Personality and Social Psychology, 52 (6), 1122-1131.

Isen, A.M., Rosenzweig, A.S., and Young, M.J. (1991) The influence of positive affect on clinical problem-solving. Medical Decision Making, 11 (3), 221-227.

Izard, C.E. (1991) The psychology of emotion, New York, N.Y.: Plenum Press.

Keltner, D., Gruenfeld, D. H., and Anderson, C. (2003) Power, approach, and inhibition. Psychological Review, 110 (2), 265-284.

Kemper, T.D. (1978) A social interactional theory of emotions, New York, N.Y.: Wiley.

Kipnis, D. (1976) The power-holders, Chicago, Ill.: University of Chicago Press. Kipnis, D. and Schmidt, S. M. (1988) Upward-influence styles: Relationship with performance evaluations, salary, and stress. Administrative Science Quarterly, 33 (4), 528-542.

Kipnis, D., Schmidt, S.M., and Wilkinson, I. (1980) Intraorganizational influence tactics: Explotations in getting ones way. Journal of Applied Psychology, 65 (4), 440-452.

Kramer, R. M., Newton, E., and Pommerenke, P. L. (1993) Self-enhancement biases and negotiator judgment: Effects of self-esteem and mood. Organizational Behavior and Human Decision Processes, 56 (1), 110-133. Lawler, E. J. (1992) Power processes in bargaining. Sociological Quarterly, 33 (1), 17-34.

(2001) An affecr theory of social exchange. American Joumal of Sociology, $107(2), 321-352$.

(2007) Affect and group attachments: The role of shared responsibility. In C. Anderson, M. Neale, and E. Mannix (Eds.), Research on managing groups and teams, Vol. IX: Affect and Groups (pp. 185-216), Amsterdam: Elsevier.

Lawler, E. J., Ford, R. S., and Blegen, M. A. (1988) Coercive capability in conflict: A test of bilateral deterrence versus conflict spiral theory. Soctal Psychology Quarterly, 51 (2), 93-107. 
Lawler, E. J. and Thye, S. R. (1999) Bringing emotions into social exchange theory. Annual Review of Sociology, 25, 217-244.

Lawler, E. J., Thye, S. R., and Yoon, J. (2000) Emotion and group cohesion in producrive exchange. American Journal of Sociology, 106 (3), 616-657.

Lawler, E. J. and Yoon, J. (1993) Power and the emergence of commitment behavior in negotiated exchange. American Sociological Review, 58 (4), $465-481$.

(1996) Commitment in exchange relations: Test of a theory of relational cohesion. American Sociological Review, 61 (1), 89-108.

(1998) Network structure and emotion in exchange relations. American Sociological Review, 63 (6), 871-894.

Lovaglia, M.J. (1994) Relating power to status. In E.J. Lawler and B. Markovsky (Eds.), Advances in group processes (Vol. XI, pp. 87-111), Greenwich, Conn.: JAI Press.

(1995a) Power and status: Exchange, attribution, and expectation states. Small Group Research, 26 (3), 400-426.

(1995b) Status, emotion, and structural power. In J. Szmatka, J. Skvoretz, and J. Berger (Eds.), Status, network and structure (pp. 159-178), Stanford, Calif.: Stanford University Press.

Lovaglia, M. J. and Houser, J. A. (1996) Emotional reactions and starus in groups. American Sociological Review, 61 (5), 867-883.

Molm, L. D. (1987) Extending power dependence theory: Power processes and negative outcomes. In E.J. Lawler and B. Markovsky (Eds.), Advances in group processes (Vol. IV, pp. 178-198), Greenwich, Conn: JAI Press.

(1990) Structure, action, and outcomes: The dynamics of power in social exchange. American Sociological Review, 55 (3), 427-447.

(1991) Affect and social exchange: Satisfaction in power-dependence relations. American Sociological Review, 56 (4), 475-493.

(1997) Coercive power in social exchange, Cambridge and New York, N.Y.: Cambridge University Press.

Ng, S.H.(1980) The social psychology of power, San Diego, Calif.: Academic Press.

O'Connor, K. M. and Arnold, J. A. (2001) Distributive spirals: Negotiation impasses and the moderating role of disputant self-efficacy. Organizational Bebavior and Human Decision Processes, 84 (1), 148-176.

Piskorski, M. J. and Tiziana, C. (2006) When more power makes actors worse off: Turning a profit in the american economy. Social Forces, 85 (2), 1011-1036.

Proell, C.A. (2007) Movin' on up: A theoretical model of power change. Unpublished manuscript. 
Schoenewolf, G. (1990) Emotional contagion: Behavioral induction in individuals and groups. Modern psycho-analysis, 15, 49-61.

Sinaceur, M. and Tiedens, L.Z. (2006) Get mad and get more than even: When and why anger expression is effective in negotiations. Journal of Experimental Social Psychology, 42 (3), 314-322.

Tedeschi, J. T., Schlenker, B. R., and Bonoma, T. V. (1973) Conflict, power, and games: The experimental study of interpersonal relations, Chicago, Ill.: Aldine.

Thibaut, J.W. and Kelley, H.H. (1959) The social psychology of groups, New York, N.Y.: Wiley.

Thye, S. R., Lawler, E. J., and Yoon, J. (2007) Social exchange and the maintenance of order in status stratified systems. Unpublished manuscript.

Tiedens, L. Z. (2001) Anger and advancement versus sadness and subjugation: The effect of negative emotion expressions on social status conferral. Journal of Personality and Social Psychology, 80 (1), 86-94.

Totterdell, P. (2000) Catching moods and hitting runs: Mood linkage and subjective performance in professional sport teams. Journal of Applied Psychology, 85 (6), 848-859.

Totterdell, P., Kellett, S., Teuchmann, K., and Briner, R. B. (1998) Evidence of mood linkage in work groups. Journal of Personality and Social Psychology, 74 (6), 1504-1515.

Van Kleef, G.A., De Dreu, C.K.W., and Manstead, A.S.R. (2004) The interpersonal effects of anger and happiness in negotiations. Journal of Personality and Social Psychology, 86 (1), 57-76.

Van Kleef, G. A., De Dreu, C. K. W., Pietroni, D., and Manstead, A.S.R. (2006) Power and emotion in negotiation: Power moderates the interpersonal effects of anger and happiness on concession making. European Journal of Social Psychology, 36 (4), 557-581.

Weiner, B. (1985) An attributional theory of achievement-motivation and emotion. Psychological Review, 92 (4), 548-573.

Willer, D. (2003) Power-at-a-distance. Social Forces, 81 (4), 1295-1334.

Willer, D., Lovaglia, M. J., and Markovsky, B. (1997) Power and influence: A theoretical bridge. Social Forces, 76 (2), 571-603.

Yukl, G. and Falbe, C. M. (1990) Influence tactics and objectives in upward, downward, and lateral influence attempts. Journal of Applied Psychology, 75 (2), 132-140.

Yukl, G. and Tracey, J. B. (1992) Consequences of influence tactics used with subordinates, peers, and the boss. Journal of Applied Psychology, 77 (4), $525-535$. 